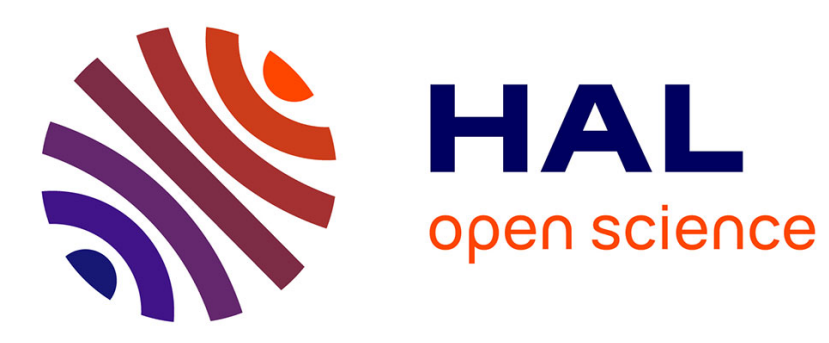

\title{
Time-resolved 3D characterisation of flow and dissolution patterns in a single rough-walled fracture
}

Catherine Noiriel, Philippe Gouze, Benoît Madé

\section{To cite this version:}

Catherine Noiriel, Philippe Gouze, Benoît Madé. Time-resolved 3D characterisation of flow and dissolution patterns in a single rough-walled fracture. Jirí Krásný (Editor), John M. Sharp (Editor). Groundwater in fractured rocks, Taylor \& Francis, pp.629-642, 2007, IAH Selected Paper Series, volume 9 (Selected Papers on Hydrogeology). hal-00350569

\section{HAL Id: hal-00350569 \\ https://hal.science/hal-00350569}

Submitted on 13 Dec 2010

HAL is a multi-disciplinary open access archive for the deposit and dissemination of scientific research documents, whether they are published or not. The documents may come from teaching and research institutions in France or abroad, or from public or private research centers.
L'archive ouverte pluridisciplinaire HAL, est destinée au dépôt et à la diffusion de documents scientifiques de niveau recherche, publiés ou non, émanant des établissements d'enseignement et de recherche français ou étrangers, des laboratoires publics ou privés. 


\title{
Time-resolved 3D characterisation of flow and dissolution patterns in a single rough-walled fracture
}

\author{
Catherine NOIRIEL ${ }^{(1,2)}$, Philippe GOUZE ${ }^{(1)}$ and Benoît MADÉ ${ }^{(2)}$ \\ (1) Laboratoire de Tectonophysique, Institut des Sciences de la Terre, de l'Environnement et de l'Espace, CNRS - \\ Université de Montpellier II, 34095 Montpellier cedex 5, France \\ (2) Centre de Géosciences, École des Mines de Paris, UMR 7619, 77305 Fontainebleau cedex, France \\ (catherine.noiriel@free.fr)
}

\begin{abstract}
An application of X-ray computed microtomography (XCMT) for 3D measurement of fracture geometry is presented. The study demonstrates the ability of XCMT to non-invasively measure the fracture walls and aperture during the course of a reactive flow experiment. The method allows estimation of both the local and global scale dissolution kinetics of a fractured limestone sample percolated by acidic water. The measured fracture geometry was then used as an input for flow modelling, in order to compare the hydraulic aperture calculated by numerical simulation with different evaluations of the aperture: hydraulic aperture measured from pressure drop during the flow experiment, mechanical aperture measured with XCMT, and chemical aperture deduced from calcium removal in the sample. The effects of reactive transport on geometry and fluid flow are discussed. Dissolution appears heterogeneous at both the small scale due to the presence of insoluble clays in the rock, and at larger scales with the formation of preferential flow pathways. These heterogeneous dissolution patterns are not predictable simply by the identification of the areas of higher fluid velocity, where transport of the chemical reaction products (i.e. rate of aperture increase) is presumed to be higher.
\end{abstract}

\section{INTRODUCTION}

Fractures strongly control the flow and transport of fluids and pollutants in low-permeability rocks. Dissolution (or precipitation) processes may strongly influence the fracture geometry and consequently the hydraulic properties such as permeability and dispersivity. The prediction of flow and transport evolution in fractures is challenging, but appears essential to evaluate long term behaviour of geothermal systems, nuclear waste storage or $\mathrm{CO}_{2}$ injection in depleted reservoirs. Carbonated environments, which supply an important part of the accessible potable water resources of the planet, are particularly sensitive to fluid-rock transfer processes over relatively short time periods. Karst formation is certainly the most remarkable example of limestone alteration.

A lot of experimental and numerical studies have been devoted to quantifying the control of various physical parameters on fluid flow and solute dispersion into fractures. Fracture roughness, aperture and surface correlation, tortuosity and contact areas have been pointed out as the essential parameters controlling flow and transport in fractures (Witherspoon at al., 1980; Tsang, 1984; Adler and Thovert, 1999; Zimmerman and Yeo., 2000). Initially, the fracture characteristics are forced by the mechanical processes of rupture and displacement (Yeo et al., 1998; Unger and Mase, 1993). In parallel, the geometry may be altered considerably by dissolution and precipitation that can feedback into the flow and transport properties. It is probable that in many applications, relevant either to geological timescale modelling or predicting system feedback to anthropogenic forcing, fracture parameters must be considered as variables.

Transport of solutes in a fracture is described by the following macroscopic equation:

$$
\partial_{t} C=\mathbf{u} \nabla C-\mathbf{D} \nabla^{2} C+R(C)
$$

where $C$ is the concentration of the species, $\mathbf{u}$ is the velocity vector (whose components are $u_{x}, u_{y}$ and $u_{z}$ ), $\mathbf{D}$ is the hydrodynamic dispersion tensor and $R(C)$ is the geochemical source term proportional to the dissolution rate. Hydrodynamic dispersion involves Taylor and geometrical dispersion, and molecular diffusion. In a fracture, solute transport is mainly controlled by the chemical reaction rate and the heterogeneity in the flow velocity. Positive feedback between flow regime and geochemical alteration can also occur, leading to instabilities and localization of the dissolution. The dominant parameters that control these phenomena at the macroscale are the Peclet number $(P e)$, the Damköhler number $(D a)$ and the aperture variability, expressed as the ratio between the aperture standard 
deviation and its mean $\left(\sigma_{a} / \bar{a}\right)$ (Dijk and Berkowitz, 1998; Hanna and Rajaram, 1998; Cheung and Rajaram, 2002; Verberg and Ladd, 2002; Szymczak and Ladd, 2004). O’Brien et al. (2003) assume that the initial fracture geometry plays an important role in determining the dissolution front and suggest that a better understanding of the heterogeneities in fractures is necessary to accurately model the reactive transport. Experimental effort is required to predict long-term evolution of such heterogeneous systems. However, experimental studies of fracture behaviour and related parameters during dissolution are limited (Durham et al., 2001; Detwiler et al., 2003; Dijk et al., 2002; Polak et al., 2004) and do not always include direct permeability and geometry measurements.

The aim of this paper is to present a methodology to study dissolution effects in a fracture by coupling chemical and hydrodynamic measurements with observation and quantification of the structural changes using X-ray microtomography. After a description of the experimental procedure (section 1), the measured changes to the fracture morphology and dissolution kinetics are presented (section 2). The measured fracture morphology was then used as input for numerical flow simulation. Afterwards, a comparison is made between the four different methods used to evaluate the changes to the fracture morphology: chemical and hydraulic measurements, imagery and flow simulation. Finally, the effect of rock mineralogy on flow, transport and geometry changes is discussed in section 3 .

\section{EXPERIMENTAL PROCEDURE}

The experiment consisted of the percolation of an acidic fluid through a rough fracture. The rock was a slightly argillaceous micritic limestone containing about $10 \%$ silicate minerals (principally clays with a minor amount of quartz). A core of $15 \mathrm{~mm}$ long and $9 \mathrm{~mm}$ diameter was fractured using a Brazilian-like test to produce a longitudinal fracture parallel to the core axis, i.e. an increasing loading charge is applied on the core edges until rupture occurs. Fracture edges were rigidified with epoxy resin in order to prevent any mechanical displacement of the fracture walls. Dissolution was obtained by flowing, at a constant rate of $2.7810^{-9} \mathrm{~m}^{3} \cdot \mathrm{s}^{-1}\left(10 \mathrm{~cm}^{3} \cdot \mathrm{h}^{-1}\right)$ water equilibrated with carbon dioxide at the partial pressure of $0.1 \mathrm{MPa}$ (controlling the inlet $\mathrm{pH}$ value at 3.9). The pressure at the outlet was maintained at $0.13 \mathrm{MPa}$ in order to avoid $\mathrm{CO}_{2}$ degassing in the circuit. The total duration of the experiment was $118.5 \mathrm{~h}$, during which the fluid effluent was periodically sampled to evaluate the mineral mass removed. Permeability was calculated from the pressure difference between sample inlet and outlet $(\Delta P)$ using steady state flow method at the initial state $\left(t_{0}\right)$ and after the two stages of dissolution $\left(t_{1}=70.5 \mathrm{~h}\right.$ and $t_{2}=118.5 \mathrm{~h}$ from the start of the experiment). At the same time, X-ray computed microtomography (XCMT) was used non-invasively to observe the tri-dimensional geometry of the sample with a spatial resolution (pixel size) of $4.91 \mu \mathrm{m}$.

$\mathrm{XCMT}$ is based on the $3 \mathrm{D}$ reconstruction of one thousand X-ray radiographies of the sample taken at different view angles on 180 degrees. The ID19 beam line of the European Synchrotron Radiation Facility (Grenoble, France) was used for this study. An area of about $10 \times 10 \mathrm{~mm}(2048 \times 2048$ pixels) located near the sample inlet is covered. After data processing (see Noiriel et al., 2005), 3D grey-level images represent the X-ray attenuation by the material in each point (voxel) in the space. As the sample is composed of only two materials (air and matrix) with different X-ray attenuation properties, histograms of grey-level attenuation are bimodal. By convention dark voxels correspond to low density material (void) and white voxels correspond to high density material (matrix). A segmentation procedure based on region growing is then used to convert grey-scale image into binary image (Nikolaidis and Pitas, 2001). Once voids and matrix are labelled in the image, it is easy to calculate the volume occupied by the fracture voids, the elevation of the lower and upper fracture walls $\left(h_{y, z}^{-}{ }^{-}\right.$and $\left.h_{y, z}^{+}\right)$, the local aperture $\left(a_{y, z}\right)$, and the area of the fluid-rock interface (Gouze et al., 2003). Figure 1 presents fracture aperture and surfaces obtained using XCMT after appropriate image processing. 


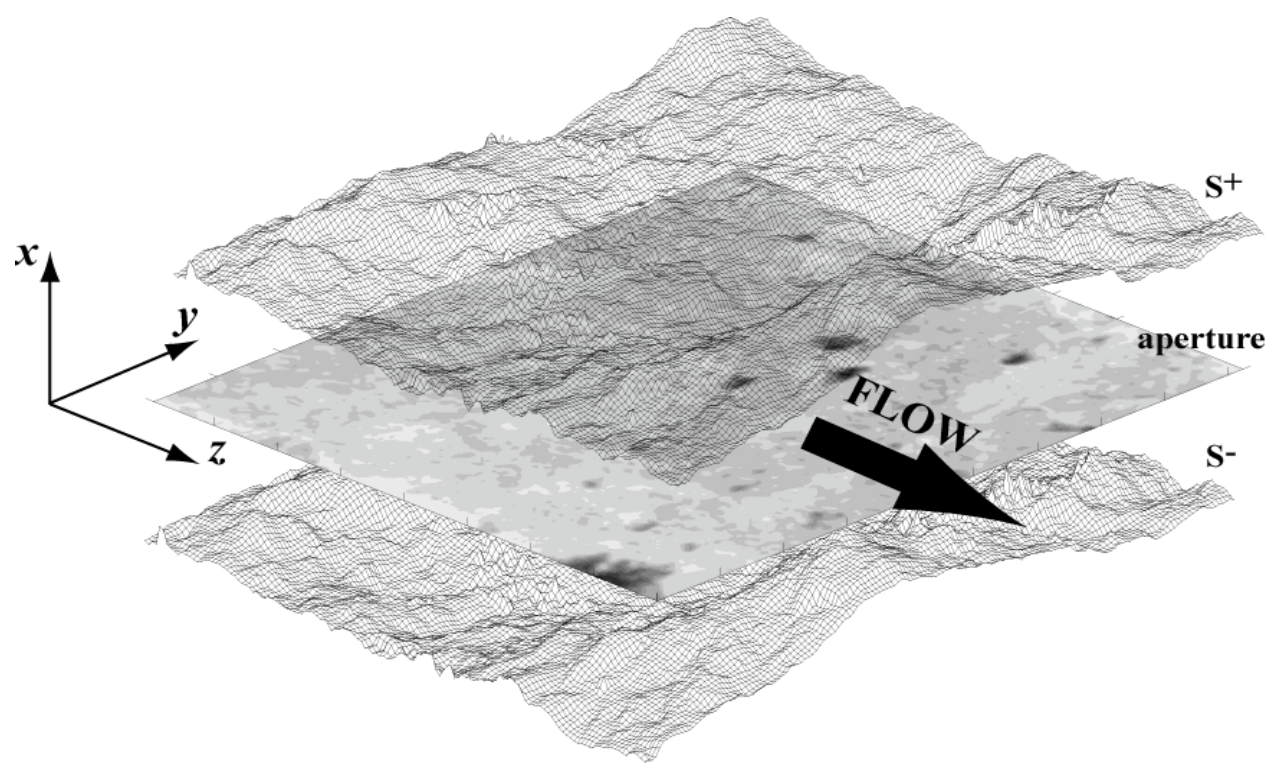

Figure 1. Upper $\left(\mathrm{S}^{+}\right)$and lower $\left(\mathrm{S}^{-}\right)$surface and aperture representation of the fracture, measured at $t_{0}$ over a $9.25 \times 7.95 \mathrm{~mm}$ region. Surfaces and aperture are obtained from processed XCMT data. Note that the grid lines are under-sampled by a factor 12 to allow visual representation.

\section{RESULTS}

\subsection{GEOMETRIC FEATURES OF FRACTURE}

The statistics and features of changes to the fracture morphology during dissolution were studied. The mechanical aperture $a_{m}$ is deduced from the local aperture:

$$
a_{m}=\bar{a}_{x, y}=\frac{1}{L l} \sum_{y=0}^{y=l} \sum_{z=0}^{z=L} a_{y, z}
$$

where $a_{y, z}$ is the local aperture at the $(y, z)$ location, $\bar{a}$ denotes the spatial average, and $L$ and $l$ are the fracture length and width, respectively. Statistical results are listed in Table 1, while aperture maps and histograms at the different stages of dissolution are displayed in Figure 2. An example of the cross section is also given in Figure 3. Dissolution effects appear to be different at two different scales.

\subsubsection{MICROSCALE PATTERN}

At the microscale (grain-scale, i.e. a few tens of microns), the different kinetic rates of dissolution between the minerals forming the rock cause heterogeneous dissolution to occur. As kinetics of clay and quartz dissolution is several orders lower than for calcite, these minerals remain at the fracture surface until they are flushed by the flowing fluid. As dissolution progresses, the fluid-rock interface appears rougher (Figure 3). Consequently, both the standard deviation for elevation of the surfaces $\left(\sigma_{s}\right)$ and micro-roughness factor of the fracture surface $\left(z_{2}\right)$ increase. Here $z_{2}$ is the root mean square of the first derivative of the surface asperity height (Myers, 1962):

$$
z_{2}=\sqrt{\frac{1}{L l} \sum_{y=1}^{y=l} \sum_{z=1}^{z=L}\left(h_{y, z+1}-h_{y, z}\right)^{2}}
$$

The presence of secondary fracture branches initially present in the sample promotes the detachment and displacement of rock fragments as soon as their size is sufficiently reduced by dissolution. As a result, the aperture is locally reduced as observed in Figure 2, b.

\subsubsection{MACROSCALE PATTERN}

At the macroscale (sample-scale), dissolution substantially affects the shape of the aperture distribution. Before dissolution, the topography of the fracture aperture can be represented as a bellshaped distribution with positive kurtosis (2.43) and skewness (1.94); positive values indicate that the 
distribution is slightly pointed and present an asymmetry toward the large values in comparison with a Gaussian distribution. Results are similar to those usually observed experimentally or assumed in models of fracture generation. But as a consequence of dissolution, the histogram evolves toward a bimodal distribution due to the formation of preferential flow pathways in the fracture (Figure 2, d). Heterogeneous dissolution at the two different scales is accompanied by a large increase of the standard deviation of mechanical aperture $\left(\sigma_{a}\right)$. As a consequence, despite the increase of the mechanical aperture $a_{m}$, the ratio $a_{m} / \sigma_{a}$ is stable during the experiment.

The cross-correlation value between the two fracture walls is defined by:

$$
\rho_{S^{+}-S^{-}}=E\left[\left(h^{+}(y, z)-\bar{h}^{+}\right)\left(h^{-}(y, z)-\bar{h}^{-}\right)\right] / E\left[\left(h^{+}(y, z)-\bar{h}^{+}\right)^{2}\right] E\left[\left(h^{-}(y, z)-\bar{h}^{-}\right)^{2}\right]
$$

where $h^{+}$and $h^{-}$is the elevation at the $(y, z)$ location of the upper and lower fracture wall, respectively and $\bar{h}$ denotes the spatial average. At the start of the experiment the two fracture walls are perfectly correlated, but dissolution induces a progressive decorrelation of the fracture walls (Table 1).

Table 1. Statistics of the fracture geometry. Definitions are provided in the text.

\begin{tabular}{|c|c|c|c|}
\hline time $(\mathrm{h})$ & $t_{0}=0$ & $t_{1}=70 \mathrm{~h} 30$ & $t_{2}=118 \mathrm{~h} 30$ \\
\hline$a_{m}(\mu \mathrm{m})$ & 40.5 & 328.0 & 418.5 \\
\hline$\sigma_{a}(\mu \mathrm{m})$ & 18.8 & 92.2 & 163.9 \\
\hline$a_{m} / \sigma_{a}$ & 2.17 & 3.57 & 2.56 \\
\hline$\sigma_{s}(\mu \mathrm{m})$ & 233.0 & 235.1 & 244.3 \\
\hline$z_{2}$ & 3.70 & 4.02 & 7.98 \\
\hline$\rho_{S^{+}-S^{-}}$ & 1.00 & 0.92 & 0.77 \\
\hline
\end{tabular}
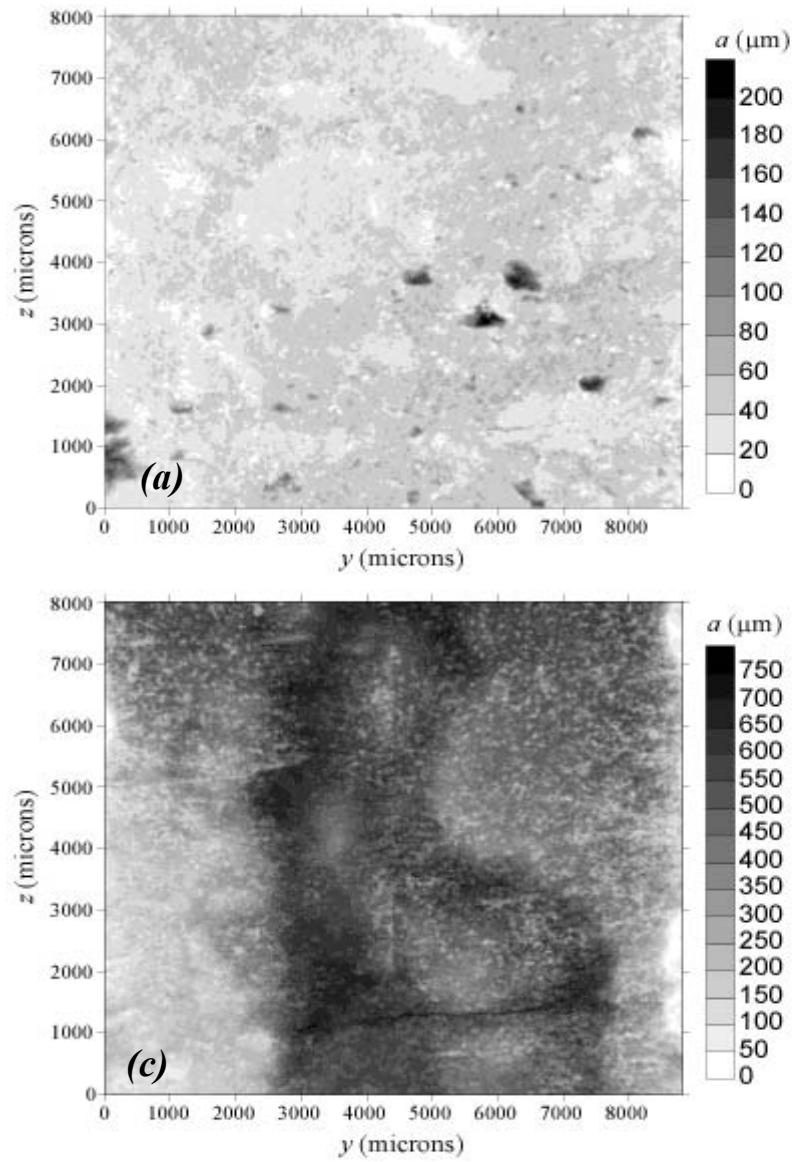
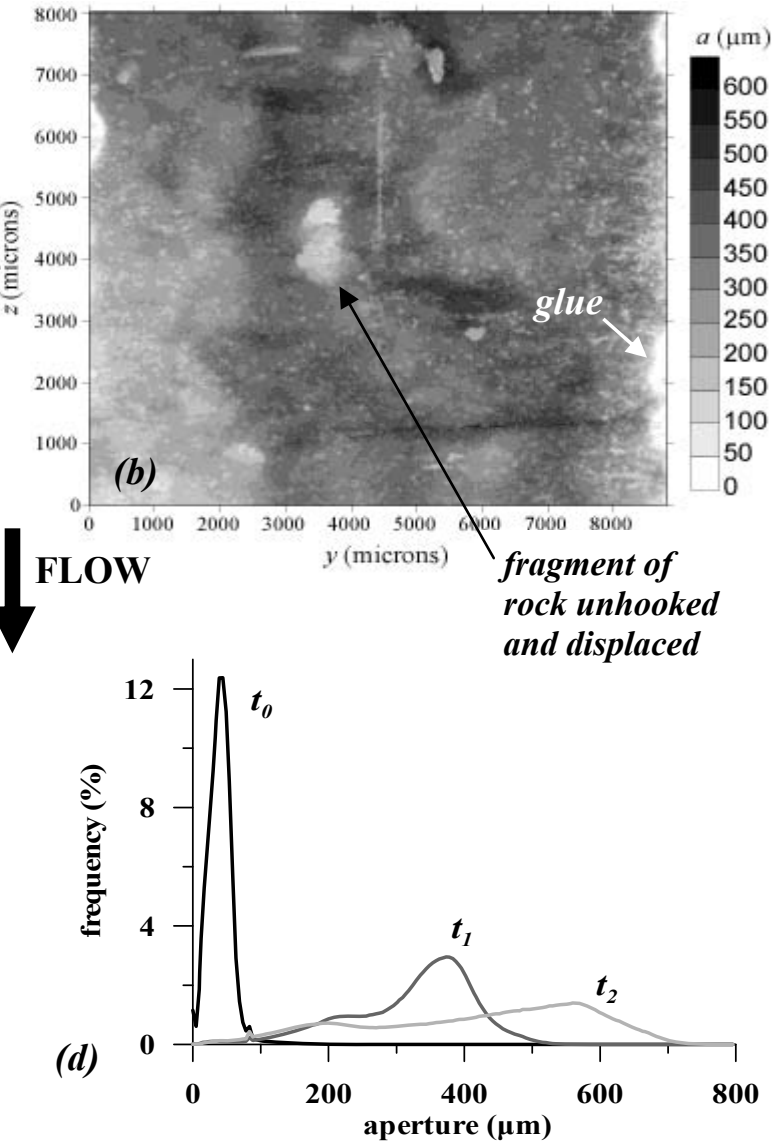

Figure 2. Aperture distribution $(\mu \mathrm{m})$ within the fracture: $(a)$ map at $t_{0},(b)$ at $t_{l}$ and $(c)$ at the end of the experiment $\left(t_{2}\right)$. The maps are voluntarily under-sampled by a factor 12 to allow better visualisation; note that the zero aperture areas on the edges of the maps correspond to epoxy resin spacer used to 
avoid closure of the fracture during the experiment. $(d)$ Histograms of aperture distribution at the different time of experiment.

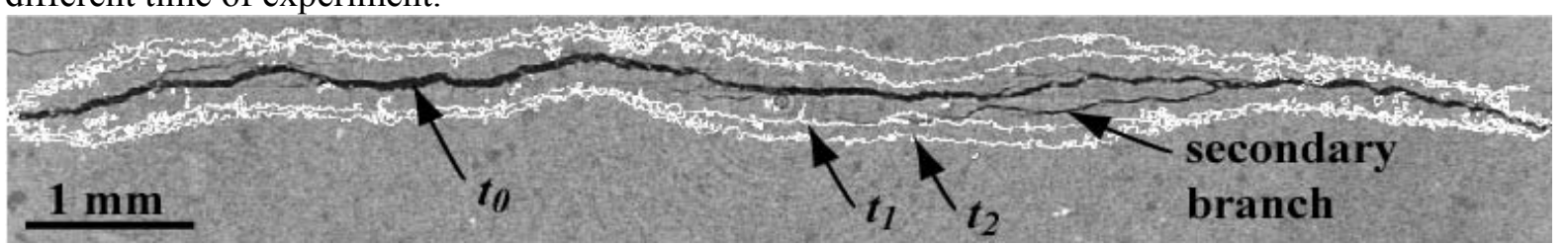

Figure 3. Visualisation of morphology changes in course of the experiment (2D cross-section). The grey level background displays the initial fracture geometry $\left(t_{0}\right)$. The white lines correspond to the fracture wall position at $t_{1}$ and $t_{2}$. Initially the fracture contains secondary branches which result from the fracturing process.

\subsection{DISSOLUTION RATE CALCULATION}

The calcium flux at the sample outlet can be related to the global (sample-scale) dissolution rate. It was variable but on the whole slightly decreased during the course of the experiment. Assuming that the sample is $90 \%$ calcite, that the molar volume of the clays and silicates was comparable to that of calcite, and that dissolution of the fracture walls was homogeneous, the aperture increase can be deduced from the following equation:

$\partial_{t} a_{c}=-\left(Q \times v_{\text {calcite }} \times \Delta C a\right) /\left(0.9 \times A_{s}\right)$

where $a_{c}$ denotes the "chemical" aperture, $Q$ is the flow rate, $v_{\text {calcite }}$ is the molar volume of calcite, $\Delta C a$ is the calcium concentration removed by the acidic fluid between sample inlet and outlet, and $A_{s}$ is the surface area of equivalent planar fracture walls. Assuming that the kinetic rate of dissolution was unchanged between the two experimental stages $\left(t_{0}-t_{1}\right.$ and $t_{1}-t_{2}$, respectively), the spatial distribution of the dissolution rate is obtained by subtracting aperture distribution after registration of the images in the same spatial referential. The local aperture change with time is given by:

$\partial_{t} a=\left(a_{t i+1}-a_{t i}\right) /\left(t_{i+1}-t_{i}\right)$

Then, the local rate of dissolution $k_{d}$ is given by:

$k_{d}=\left(\partial_{t} a \times S_{\text {pix }}\right) /\left(v_{\text {calcite }} \times S_{r}\right)$

where $S_{p i x}$ is the pixel area $\left(4.91 \times 4.91 \mu \mathrm{m}^{2}\right)$ and $S_{r}$ is the reactive surface area of the mineral. As $S_{r}$ is an unknown parameter, it is chosen to be equal to the geometric surface area, i.e. $S_{p i x}$. The results for the dissolution stages $t_{1}-t_{0}$, and $t_{2}-t_{1}$ are reported in Figure 4. Maps show that the dissolution rate is heterogeneous both in the flow direction and perpendicularly to it, $k_{d}$ ranging from 0 to $6.010^{-9} \mathrm{~mol} . \mathrm{m}^{-}$ ${ }^{2} \cdot \mathrm{s}^{-1}$.

Three major phenomena potentially control the rate of calcite dissolution, $k_{d}$. The first phenomenon concerns the level of disequilibrium of the solution in regards with the calcite mineral. It is commonly assumed that the rate of dissolution is proportional to the saturation index $\Omega: k_{d} \propto(1-\Omega)^{n}$, with $n \in$

$\mathbb{R}$ (Lasaga, 1998). The saturation index increases as far as the reaction progress towards equilibrium $(\Omega \rightarrow 1)$, so $k_{d}$ decreases accordingly. In the experiment, the solution remains undersaturated with respect to calcite $(\Omega \sim 0.15$ at the outlet), so that the influence of $\Omega$ is relatively weak. The second phenomenon concerns the dissolution kinetics of calcite at low $\mathrm{pH}$ values. Far from equilibrium and at relatively low $\mathrm{pH}($ e.g. $\mathrm{pH}<5.5)$, the kinetic rate of calcite dissolution $(k)$ is $\mathrm{pH}$ dependent (Plummer et al., 1978). Because protons $H^{+}$are consumed during the chemical reaction of calcite dissolution, $\mathrm{pH}$ increases progressively during the chemical reaction, so the kinetic rate of dissolution decreases. In the experiment $\mathrm{pH}$ increases progressively from $3.9 \pm 0.1$ (corresponding to $\mathrm{pH}$ of the inlet fluid equilibrated with $\mathrm{CO}_{2}$ at the partial pressure of $0.1 \mathrm{MPa}$ ) to $5.3 \pm 0.2$, as the fluid goes along the fracture and reactions between $\mathrm{CO}_{2}$ (aq), $\mathrm{H}^{+}$and calcite occur. According to the equation given by Plummer et al. (1978) to describe the kinetic rate of calcite dissolution as a function of $\mathrm{pH}$ and $P_{\mathrm{CO} 2}, k$ decreases theoretically from $7.710^{-9} \mathrm{~mol} . \mathrm{m}^{-2} . \mathrm{s}^{-1}$ at $\mathrm{pH} 3.9$ to $1.5410^{-9} \mathrm{~mol} \cdot \mathrm{m}^{-2} \cdot \mathrm{s}^{-1}$ at $\mathrm{pH} 5.3$. In others words, $k$ is reduced by a factor 5 . This phenomenon caused the dissolution rate to be greater at the sample inlet (Figure 5). But the ratio between averaged aperture estimated at the inlet and outlet is about 1.8 both after $t_{1}$ and $t_{2}$, which is lower than the value of 5 expected by the model of Plummer et 
al. (1978). The third phenomenon concerns the control of the reaction. For calcite at low $\mathrm{pH}$, the kinetic rate of the chemical reaction at the solid surface $k_{S}$ is substantially faster than the kinetics of diffusion of reactants and products close to the surface $k_{T}$ (Rickard and Sjöberg, 1983). So the global kinetics of reaction is limited by the mass transfer of reactants and products at the fluid-rock interface. In moving solution, the advective transport is substantially faster than molecular diffusion; therefore the advective transport near the fluid-rock interface can control the rate of reaction. As the flow is localized in channels, fluid velocity in the fracture edges becomes slow compared to velocity in the channels (see next section). The dissolution is then localized where transport is higher, i.e. in the preferential flow pathways (Figure 4, $a$ and $b$ ).
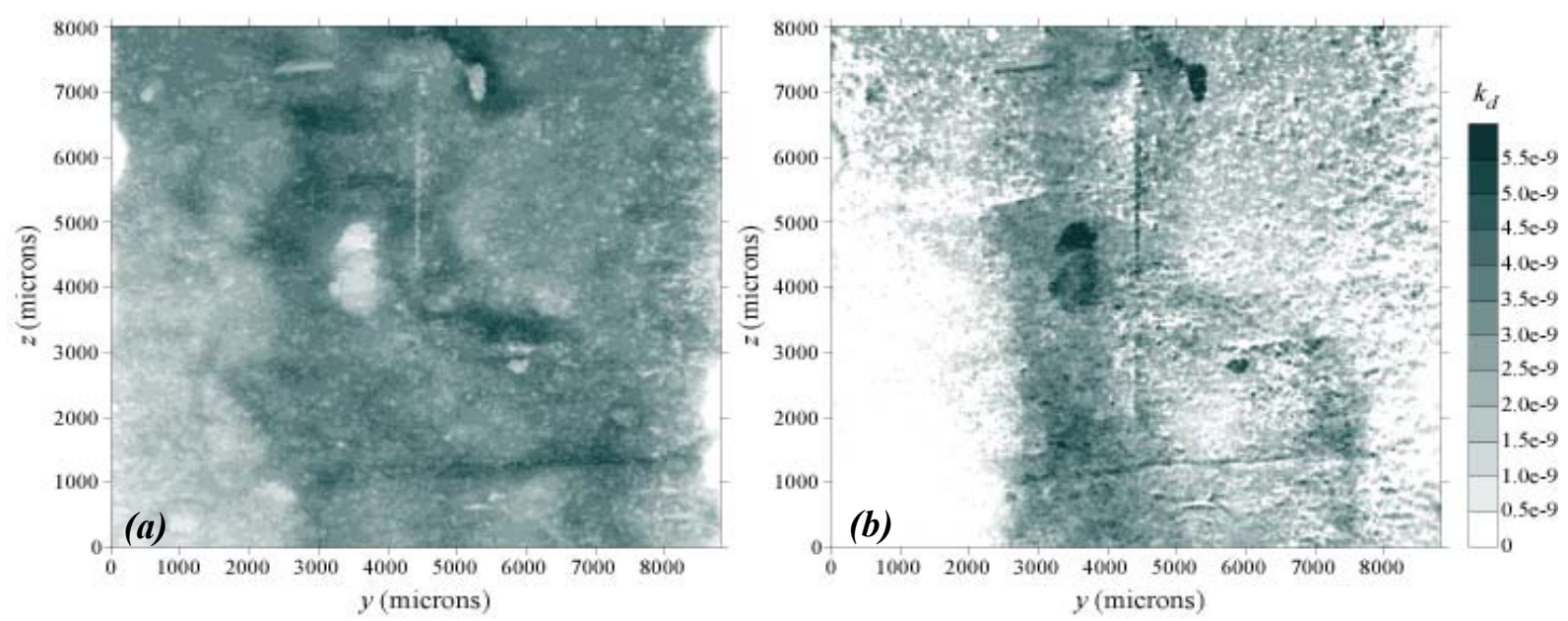

Figure 4. Distribution of the computed rate of dissolution $k_{d}\left(\mathrm{~mol} \cdot \mathrm{m}^{-2} \cdot \mathrm{s}^{-1}\right)$ corresponding to the dissolution stage $(a) t_{0}-t_{1}$ and $(b) t_{1}-t_{2}$.

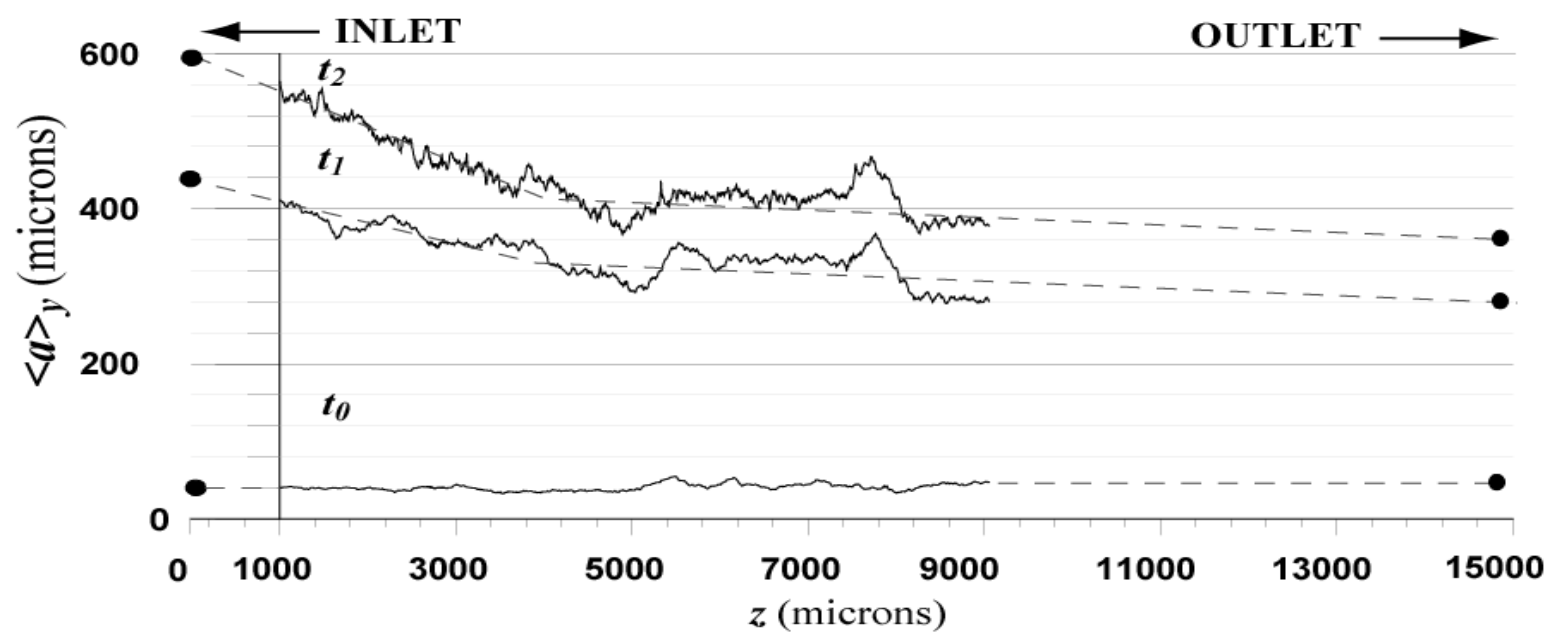

Figure 5. Aperture average along the flow axis showing that dissolution is more pronounced near the sample inlet. Black lines represent aperture calculated from experimental data; black dots represent estimation of the aperture at the sample inlet and outlet.

\subsection{FLOW SIMULATION}

The finite volume code Fluent ${ }^{\circledR}$ was used to solve the flow equations in a $9.25 \times 7.95 \mathrm{~mm}$ region of the fracture at $t_{0}, t_{1}$ and $t_{2}$. A computational grid of 423,900 elements was generated from two fracture walls extracted from the XCMT images. Pixel size renormalisation (initially $4.91 \mu \mathrm{m}$ in all directions) was applied to allow tractable computation of the 3D flow field. Finally, the fracture was square meshed by $157 \times 135$ elements of size $58.92 \mu \mathrm{m}$ in the $y$ - $z$ plane. The fracture aperture ( $x$-direction) was meshed by 20 elements of variable size; cell height growing (parabolic function) from the fracture wall to the middle to refine the grid in the area of higher flow gradient and correctly simulate the quasi- 
Poiseuille flow distribution across the fracture. The boundary conditions were taken to be constant flow rate $\left(10 \mathrm{~cm}^{3} \cdot \mathrm{h}^{-1}\right)$ at the sample inlet, uniform pressure $(0.1 \mathrm{MPa})$ at the outlet, and no flux at the fracture walls. The velocity vector $\mathbf{u}$ was obtained by solving the Navier-Stokes (NS) equation system (mass and momentum conservation equations):

$$
\left\{\begin{array}{l}
\rho(\mathbf{u} \cdot \nabla) \mathbf{u}=-\nabla P+\mu \nabla^{2} \mathbf{u} \\
\nabla \cdot \mathbf{u}=0
\end{array}\right.
$$

where $P$ is the effective pressure, $\rho$ is the fluid density and $\mu$ is the dynamic viscosity.

The fluid velocity averaged in the $x$-direction is displayed for $t_{0}, t_{1}$ and $t_{2}$ in Figure 6 . Initially, the velocity field appears heterogeneous at small scales and the flow was not particularly localized. At $t_{l}$, the flow became localized in preferential pathways, and at $t_{2}$ only one principal channel remains visible. Due to the fracture opening, the mean velocity in the fracture $(\bar{u})$ decreased during dissolution, from $7.710^{-3} \mathrm{~m} \cdot \mathrm{s}^{-1}$ at $t_{0}$ to $6.110^{-4} \mathrm{~m} \cdot \mathrm{s}^{-1}$ at $t_{2}$. Despite the changes in the flow patterns, the ratio of the standard deviation to the mean fluid velocity remained almost constant during the experiment $\left(\bar{u} / \sigma_{u}\right.$ varies from 2.2 to 1.4). However, the spatial correlation of the flow velocity increases largely in the $z$-direction due to the formation of channels in the flow direction.

The shape of the velocity profiles across the fracture aperture can be classified in three types (Tenchine and Gouze, 2005): (1) profiles that are parabolic and centred in conformity with the Poiseuille equation of fluid velocity between two parallel plates: $u_{z}(x)=u_{0}\left[1-(2 x / a)^{2}\right\rfloor,(2)$ profiles that are parabolic but asymmetric and (3) profiles that are not parabolic; here $u_{0}$ is the maximum velocity in the parabolic profile. At $t_{0}, 40 \%$ of the profiles are centred-parabolic. Development of preferential flow paths, decorrelation of the surfaces and increasing roughness cause the percentage of centred-parabolic profiles to dramatically decrease (only $4 \%$ remain at $t_{2}$ ). The percentage of nonparabolic profiles increases accordingly, whereas the percentage of asymmetric profiles stays almost stable during the dissolution process (between 60-75\%). Asymmetric profiles were also observed in fractured flow by Dijk et al. (1999) when studying fluid flow using nuclear magnetic resonance imaging (NMRI).

\section{DISCUSSION}

\subsection{APERTURE}

Navier-Stokes equations for flow between two parallel plates of separation $a$ (width aperture) can be reduced to the well-known cubic law, which stipulates that the flow rate is proportional to the cube of aperture:

$Q=-a^{3} l \Delta P / 12 \mu L$

where $l$ and $L$ are the fracture width and length, respectively. The parallel plate assumption implies that both the fracture roughness and the tortuosity play no role in affecting the fluid flow. However the geometry of a natural fracture diverges more or less from the parallel plate model, and deviations to the cubic law are observed when replacing $a$ by the average mechanical aperture $a_{m}$ in equation 9 . Nevertheless, application of the cubic law remains valid if the local aperture $a$ in equation 9 is replaced by an equivalent hydraulic aperture $a_{h}$, which indirectly integrates the geometry of the fracture:

$Q=-a_{h}^{3} l \Delta P / 12 \mu L$

So the hydraulic aperture, which is measured experimentally or calculated by numerical simulation, can be compared with $a_{m}$ in order to evaluate the deviation from the cubic law. Using finite differences to resolve the local cubic law equation, Patir and Cheng (1978) performed flow between surfaces whose profiles obeyed a Gaussian distribution with linearly-decreasing autocorrelation function. The authors found that the hydraulic aperture could be fit by an exponential relation:

$a_{h-R E Y}^{3}=a_{m}^{3}\left(1-0.9 \exp \left(-0.56 a_{m} / \sigma_{a}\right)\right)$

In their model, deviation to the cubic law is expected when $a_{m} / \sigma_{a}$ is below a value of 10 . Results obtained by Brown (1987) using similar calculations on several generated fractal fractures with different fractal dimensions (from 2.0 to 2.5), and Zimmerman and Bodvarsson (1996) using high- 
order approximations for lognormal distribution of permeability fall close to equation 11 . Their results suggest that the formula is applicable to fractures with different geometrical characteristics.

For this study, the change in fracture aperture was evaluated using five different methods: (1) XCMT measurement $\left(a_{m}\right),(2)$ differential pressure recorded during experiment using equation $10\left(a_{h-E X P}\right),(3)$ differential pressure deduced from the flow numerical simulation using equation $10\left(a_{h-N S}\right)$, (4) Reynolds approximation using equation $11\left(a_{h-R E Y}\right)$, and (5) chemical aperture evaluated from equation $5\left(a_{c}\right)$. As is typically found, the hydraulic aperture calculated by Navier-Stokes simulation differs from the mechanical aperture. Initially, the difference was $24 \%$ and $a_{h-N S}$ was close to $a_{h-E X P}$ measured experimentally $\left(a_{h-E X P}=30 \mu \mathrm{m}\right)$. The effective aperture $a_{h-R E Y}$ calculated empirically from the Reynolds calculation differed from $a_{h-N S}$ but was logically intermediate between $a_{h-N S}$ and $a_{m}$ (Table 2). Large discrepancies between Reynolds numerical aperture estimates and experimental measurements were also reported by Nicholl et al. (1999), indicating that a 2D description of the flow field is inappropriate for fully describing fluid flow. According to equation 11, the deviation from the cubic law is proportional to the roughness factor $a_{m} / \sigma_{a}$. The ratio $a_{m} / \sigma_{a}$ remained stable due to the effect of the heterogeneous dissolution, although $a_{m}$ increased during the experiment. This explains why the ratios $a_{m} / a_{h-N S}$ or $a_{m} / a_{h-R E Y}$ remained almost constant. Finally, note that $a_{c}$ and $a_{m}$ are coherent; the difference is certainly due the fact that $a_{m}$ was calculated on a limited part of the fracture whereas the calculation of $a_{c}$ integrates the entire fracture.
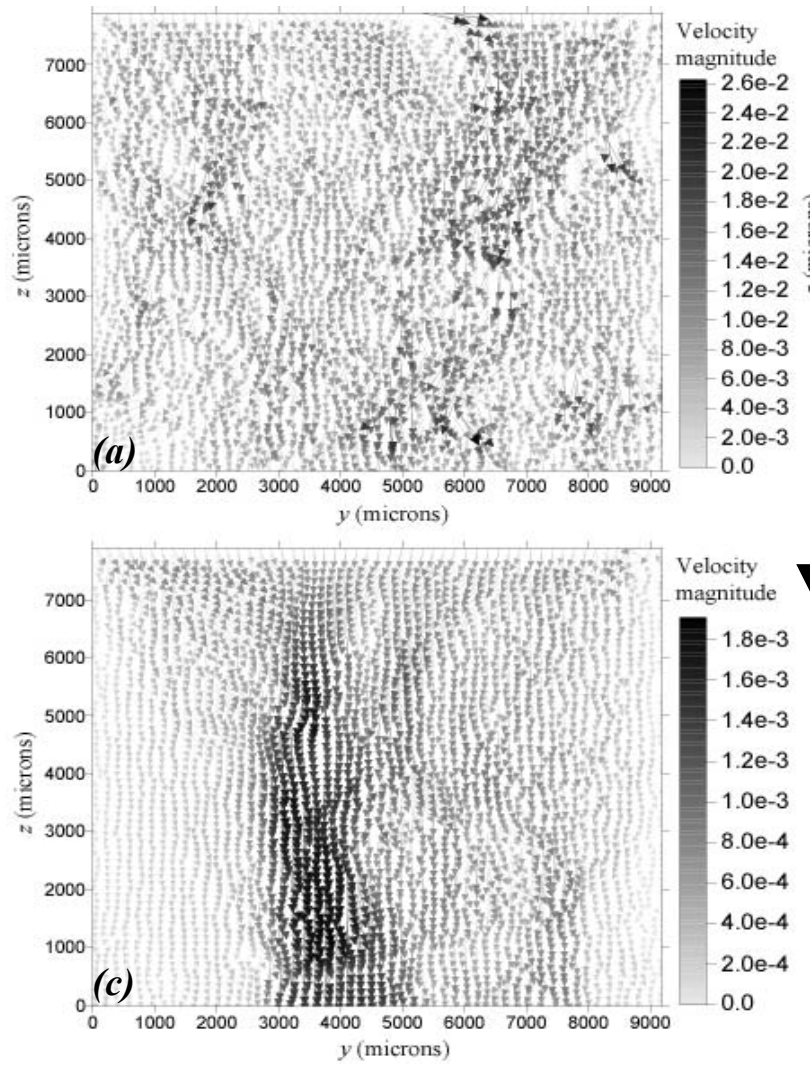

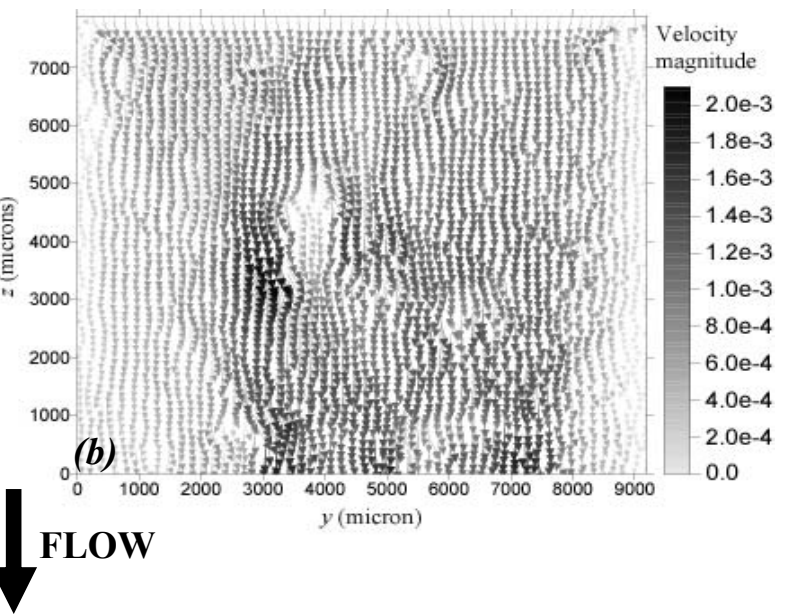

Figure 6. Velocity field (direction and intensity) from Navier-Stokes simulations in the fracture $(a)$ initially $\left(t_{0}\right),(b)$ at $t_{1}$ and $(c)$ after the experiment $\left(t_{2}\right)$.

Table 2. Comparison of the different types of aperture: mechanical aperture $\left(a_{m}\right)$, hydraulic aperture measured in the experiment $\left(a_{h-E X P}\right)$, hydraulic aperture calculated by Navier-Stokes simulation $\left(a_{h-N S}\right)$, hydraulic aperture calculated by Patir and Cheng (1978) formula $\left(a_{h-R E Y}\right)$, and chemical aperture calculated from the calcium release $\left(a_{c}\right)$.

\begin{tabular}{|c|c|c|c|c|c|}
\hline & $a_{m}$ & $a_{h-E X P}$ & $a_{h-N S}(\mu \mathrm{m})$ & $a_{h-R E Y}$ & $a_{c}$ \\
\hline initial $\left(t_{0}\right)$ & 40.5 & 30 & 32.3 & 35.8 & 40.5 \\
\hline$t_{l}$ & 328.0 & 110 & 268. & 297 & 357.5 \\
\hline final $\left(t_{2}\right)$ & 418.5 & - & 298 & 362 & - \\
\hline
\end{tabular}




\subsection{IMPLICATION OF MINERALOGY ON FLOW, TRANSPORT AND DISSOLUTION PATTERNS}

The study of Gouze et al. (2003) investigated dissolution effects on two limestone rocks with different mineralogical composition. One sample was composed almost completely of calcite, whilst a second also contained some dolomite, quartz and clay fraction $(\sim 15 \%)$. In the first case, they observed that dissolution was relatively homogeneous and could be reduced to a translation of the fracture walls. Consequently, $\sigma_{a}$ remained quasi constant and $a_{m} / \sigma_{a}$ increased from 6.2 to 12.2. So, it is expected (eq. 11) that the flow can be progressively idealized with the parallel plate model. In the second case, they showed that dissolution appeared to be very heterogeneous due to the differential kinetics between minerals. The value of $\sigma_{a}$ increased significantly and $a_{m} / \sigma_{a}$ globally decreased from 3.0 to 2.0 during the experiment. In this case, important deviations from the cubic law are expected.

Transport of solutes in a fracture is largely dependent on the chemical reaction rate and of the heterogeneity in the flow field (equation 1). The two parameters that can describe these effects are the Damköhler number $\left(D a=k_{\mathrm{d}} L / \bar{u}\right)$ and Peclet number $\left(P e=\bar{u} L / D_{m}\right.$, where $D_{m}$ is the molecular diffusion coefficient). $D a$ weighs the relative influence of chemical reaction rates to advective transport. $P e$ weighs the relative magnitude of advective to diffusive transport. When $D a$ is large, the rate of the chemical reaction is larger than the rate at which the fluid is transported. In this case, dissolution patterns depend largely on the Peclet number, as observed by Detwiler et al. (2003). At high $P e$, the dissolution is relatively homogeneous whereas at low $P e$ flow localizes in preferential channels. The process that accelerates flow localisation and channel growth is the reactive infiltration instability described by Ortoleva et al. (1987). Initial heterogeneities in the fracture aperture cause the flow to be localized in preferential paths. Since the permeability is larger within preferential paths, flow and transport are focused within these paths leading to a rapid enlargement of the channels and slower dissolution outside the channels. Thus it is expected that the development of channels is related to initial heterogeneities of the fracture aperture and flow field. During their dissolution experiment of halite using nuclear magnetic resonance imaging, Dijk et al. (2002) also noticed that mineralogy heterogeneities can have an impact on dissolution patterns particularly at low Damköhler number.

In the present study, the flow patterns at $t_{1}$ and $t_{2}$ were correlated to the fracture morphology: the larger the aperture increase, the higher the flow velocity (Figure 4 and 6). However, there wasn't any relation evident between the initial flow field at $t_{0}$ and the one after dissolution. In particular, areas of higher flow velocity at $t_{0}$, where dissolution and transport are presumed to be more important, were not correlated with the areas where channels formed. This observation is opposite to equation 1 , which stipulates that the greater the flow velocity, the greater the transport (and so the local dissolution rate). Moreover, $a_{h-E X P}$ measured experimentally at $t_{1}$ differs largely from that calculated by the other methods (Table 2). When looking more precisely at the fracture void, it can be observed that a microporous phase composed of clays and quartz remains in the fracture edges (Figure 7); the presence of these phases is underestimated in the segmentation procedure (Figure 3). So the fracture aperture and flow velocity are overestimated when clays and quartz remain in the fracture void. In consequence, head losses are probably higher than those calculated by the flow simulation, explaining that $a_{h-E X P}$ at $t_{l}$ highly differs from $a_{m}$ or $a_{h-N S}$. It is also probable than the mineral heterogeneities of the rock matrix are responsible of the unpredictable evolution of the fracture geometry with dissolution.

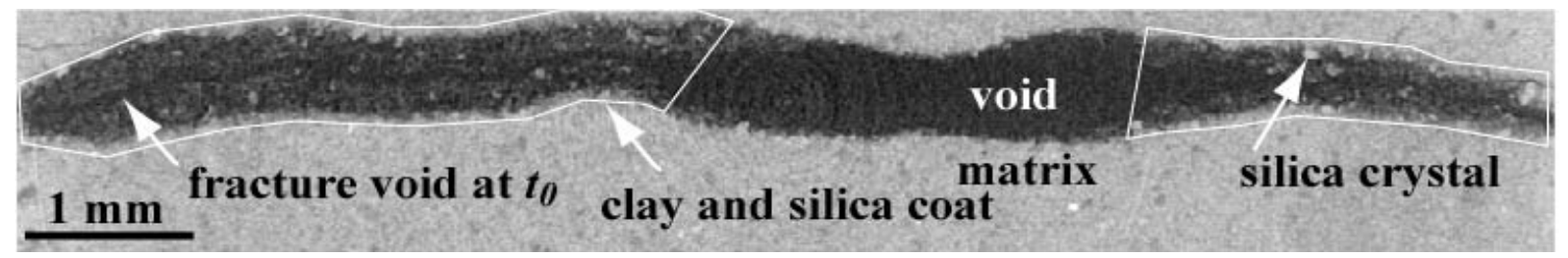

Figure 7. 2D cross-section of the fracture at the end of the experiment ( $x-y$ plane). The white layouts represent areas where clays and quartz remain in the fracture void (note that quartz crystals of 50$100 \mu \mathrm{m}$ size appear in high grey level).

\section{CONCLUDING REMARKS}


The objective of this work was to obtain well-constrained experimental data to study the effects of dissolution on fracture geometry and flow evolution. The remarkable performance of X-ray computed microtomography has proven to be an efficient tool to study structural changes from the scale close to the mineral grain-size to the scale relevant to macroscopic characterization of the processes.

Heterogeneous dissolution of the sample was observed both at micro- and macroscale $(\mu \mathrm{m}$-scale and $\mathrm{cm}$-scale). The fracture opening was subjected to perturbation due to the presence of low-solubility minerals in the rock. Numerical simulation has permitted the development of preferential flow paths to be related to the decorrelation of the surfaces and the increase of the surface roughness.

The rock mineralogy appears to be a very important parameter that controls the changes in the fracture morphology, flow and transport in response to the chemical alteration. By introducing heterogeneities at the fracture walls, the roughness factor that controls deviation to the cubic law remains unchanged despite aperture increase. Formation of a micro-porous phase in the fracture void slows down flow and transport (and by consequence the rate of aperture opening), whereas a broad channel develops when particles are removed by the fluid. In consequence, the evolution of fracture morphology in natural rocks whose mineralogical composition is variable appears to be more unpredictable than experimentally observed or predicted in mono-mineral rocks. The results indicate that further research is necessary to understand the complex coupling between chemical reactions, petrophysical properties, fracture wall morphology and flow.

\section{ACKNOWLEDGMENTS}

We thank the ESRF-ID19 team (Xavier Thibault, Elodie Boller and Peter Cloetens) for support during the data acquisition. We are also grateful to Frank Denison and the anonymous reviewer who helped us to improve the original manuscript. This work was supported by the European CommissionRDG-(EVK1-CT-2001-00091 “ALIANCE"), the CNRS and the French Ministry of Industry through the project PICOR for studying $\mathrm{CO}_{2}$ sequestration in reservoirs (RTPG-CEP\&M-G.7306).

\section{REFERENCES}

Adler, P.M. and Thovert, J.F. (1999) Fracture and fracture networks. Kluwer, Dordrecht, The Netherland, $429 \mathrm{p}$.

Brown, S.R. (1987) Fluid flow through rock joints: The effect of surface roughness. Journal of Geophysical Research, 92(B2): 1337-1347

Cheung, W. and Rajaram, H. (2002) Dissolution finger growth in variable aperture fractures: role of the tip-region flow field. Geophysical Research Letters, 29(22): 2075, doi:10.1029/2002GL015196

Detwiler, R.L., Glass, R.J. and Bourcier, W.L. (2003) Experimental observation of fracture dissolution: The role of Peclet number on evolving aperture variability. Geophysical Research Letters, 30(12): 1648, doi:10.1029/2003GL017396

Detwiler, R.L., Rajaram, H. and Glass, R.J. (2000) Solute transport in variable-aperture fractures: An investigation of the relative importance of Taylor dispersion and macrodispersion. Water Resources Research, 36(7): 1611-1625

Dijk, P. and Berkowitz, B. (1998) Precipitation and dissolution of reactive solutes in fractures. Water Resources Research, 34(3): 457-470

Dijk, P., Berkowitz, B. and Bendel, P. (1999) Investigation of flow in water-saturated rock fractures using nuclear magnetic resonance imaging (NMRI). Water Resources Research, 35(2): 347-360

Dijk, P., Berkowitz, B. and Yechieli, Y. (2002) Measurement and analysis of dissolution patterns in rock fractures. Water Resources Research, 38(2): 5-1-5-12

Durham, W.B., Bourcier, W.L. and Burton, E.A. (2001) Direct observation of reactive flow in a single fracture. Water Resources Research, 37(1): 1-12

Gouze, P., Noiriel, C., Bruderer, C., Loggia, D. and Leprovost, R. (2003) X-Ray tomography characterisation of fracture surfaces during dissolution. Geophysical Research Letters, 30(5): 1267, doi:10.1029/2002GL16755

Hanna, R.B. and Rajaram, H. (1998) Influence of aperture variability on dissolutionnal growth of fissures in karst formation. Water Resources Research, 11:2843-2853

Lasaga, A.C. (1998) Kinetic theory in the earth sciences. Princeton Univ. Press, New Jersey, 728 p. 
Myers, N.O. (1962) Characterization of surface roughness. Wear, 5: 182-189

Nicholl, M.J., Rajaram, H., Glass, R.J. and Detwiler, R.L. (1999) Saturated flow in a single fracture: Evaluation of the Reynolds equation in measured aperture field. Water Resources Research, 35(11): 3361-3373

Nikolaidis, N. and Pitas, I. (2001) 3-D image processing algorithms. John Wiley \& Sons Inc., New York, $176 \mathrm{p}$.

Noiriel C., Bernard D., Gouze P. et Thibaut X. (2005) Hydraulic properties and microgeometry evolution in the course of limestone dissolution by CO2-enriched water. Oil and Gas Science and Technology, 60(1): 177-192

O'Brien, G.S., Bean, C.J. and McDermott, F. (2003) Numerical investigations of passive and reactive flow through generic single fracture with heterogeneous permeability. Earth and Planetary Science Letters, 213: 271-284

Ortoleva P. J., Chadam J., Merino E., and Sen A. (1987) Geochemical self-organization, II. The reactive infiltration instability. American Journal of Science, 287: 1008-1040

Patir, N. and Cheng, H.S. (1978) An average flow model for determining effects of threedimensionnal roughness on partial hydrodynamic lubrication. Journal of Lubrication Technology, 100: $12-17$

Plummer, L.N., Wigley, T.M.L. and Parkhurst, D.L. (1978) The kinetics of calcite dissolution in CO2water systems at $5^{\circ}$ to $60^{\circ} \mathrm{C}$ and 0.0 to 1.0 atm CO2. American Journal of Science, 278: 179-216.

Polak, A., Elsworth, D., Bernard, Liu, J. and Grader, A.S. (2004) Spontaneous switching of permeability changes in limestone fracture with net dissolution. Water Resources Research, 40: W03502-1-10

Rickard, D. and Sjöberg, E.L. (1983) Mixed kinetic control of calcite dissolution rates. American Journal of Science, 283: 815-830.

Szymczak, P. and Ladd, A.C.J. (2004) Microscopic simulations of fracture dissolution. Geophysical Research Letters, 31: L23606, doi:10.1029/2004GL021297

Tenchine, S. and Gouze, P. (2005) Density contrast effects on tracer dispersion in variable aperture fractures. Advances in Water Resources, 28: 273-289

Tsang Y. W. (1984) The effect of tortuosity on fluid flow through a single fracture. Water Resources Research, 20(9): 1209-1215

Unger, A.J.A. and Mase, C.W. (1993) Numerical study of the hydromechanical behaviour of two rough fracture surfaces in contact. Water Resources Research, 29(7): 2101-2114

Verberg, R. and Ladd, A.C.J. (2002) Simulation of chemical erosion in rough fracture. Physical Review E, 65:056311, doi:10.1103/PhysRevE.65.056311

Witherspoon, P.A., Wang, J.S.Y., Iwai, K. and Gale, J.E. (1980) Validity of cubic law for fluid flow in a deformable rock fracture. Water Resources Research, 16(6): 1016-1024

Yeo, I.W., De Freitas, M.H. and Zimmerman, R.W. (1998) Effect of shear displacement on the aperture and permeability of a rock. International Journal of Rock Mechanics and Mining Sciences, 35(8): 1051-1070

Zimmerman, R.W. and Bodvarsson, G.S. (1996) Hydraulic conductivity of rock fractures. Transport in porous media, 23: 1-30

Zimmerman, R.W. and Yeo, I. (2000) Fluid flow in rock fractures: From the Navier-Stokes equations to the cubic law. In: B. Faybishenko, P.A. Witherspoon and S.M. Benson (eds), Dynamics of fluids in fractured rocks, Geophysical Monograph 122, pp. 213-224 